\title{
Seroepidemiology of HTLV-1 and HTLV-2 Infection in Neyshabur City, North-Eastern Iran, during 2010-2014
}

\author{
Mohammad Salehi ${ }^{1}$, Seyyed Khalil Shokouhi Mostafavi ${ }^{2}$, Abdolmajid Ghasemian $^{3}$, Mahmoud \\ Gholami $^{4}$, Abdolrahim Kazemi-Vardanjani ${ }^{* 5}$ and Mohammad Karim Rahimi ${ }^{2}$ \\ ${ }^{1}$ Medical Diagnostic Laboratory of Neyshabour, Center of Medical, Pathological and Genetic Diagnostic Services, Iranian \\ Academic Center for Education, Culture and Research (ACECR), Mashhad Branch, Mashhad, Iran; ${ }^{2}$ Department of \\ Microbiology, Islamic Azad University, Tehran Medical Science Branch, Tehran, Iran; ${ }^{3}$ Department of Microbiology, \\ Faculty of Medicine, AJA University of Medical Sciences, Tehran, Iran; ${ }^{4}$ Department of Biology, Faculty of Sciences, \\ University of Isfahan, Isfahan, Iran; ${ }^{5}$ Shahrekord University of Medical Sciences, Shahrekord, Iran
}

Received 25 October 2015; revised 20 January 2016; accepted 24 January 2016

\begin{abstract}
Background: Retroviruses of human T-lymphotropic viruses (HTLV-1 and HTLV-2) have been demonstrated to be endemic in the north-eastern region of Iran. This study was aimed to determine the HTLV-1 and HTLV-2 prevalence among healthy individuals in Neyshabur City during 2010-2014. Methods: A total of 8054 blood samples were collected from healthy participants in Neyshabur, North-Eastern Iran. The blood samples were screened for the presence of specific antibodies against HTLV-1 and HTLV-2 by using ELISA according to the manufacturer's instructions. Results: The overall seropositivity rate for HTLV-1 and HTLV-2 was found to be $6.55 \%$ (528 out of 8054) among participants. Conclusion: Both HTLV-1 and HTLV-2 were demonstrated to be at a high rate in healthy individuals. However, a smaller number of asymptomatic carriers were found in this study, as compared to those identified in previous investigations in the city. DOI: 10.6091/.21.1.57
\end{abstract}

Keywords: Human T-lymphotropic viruse, Seroepidemiology, Enzyme-linked immunosorbent assay, Iran

Corresponding Author: Abdolrahim Kazemi-Vardanjani

Shahrekord University of Medical Sciences, Shahrekord, Iran; Tel.: (+98-251) 394514760; Fax: (+98-251) 82884555;

E-mail: bacteriology94@gmail.com

\section{INTRODUCTION}

$\mathrm{H}$ uman T-lymphotropic viruses (HTLV-1 and HTLV-2), classified in the retroviridae family, are among the first identified species ${ }^{[1-3]}$. HTLV-1 and HTLV-2 are widespread all over the world and are endemic in different areas, including North-Eastern $\operatorname{Iran}^{[4-6]}$. According to a previous study, the rate of HTLV-1 infection has been reported to be less than $0.26 \%$ in Mashhad, North-Eastern Iran, while it does not exceed $0.34 \%$ in other areas of the country ${ }^{[7]}$. The prevalence of HTLV-1 infection in other countries such as Turkmenistan, Brazil, Spain, Korea and Japan was found to be $0.007 \%^{[8]}, 1.9 \%{ }^{[9]}$, $0.001 \%^{[10]}, 0.27 \%^{[11]}$, and $0.12 \%{ }^{[12]}$, respectively.
HTLV-1- and HTLV-2-infected carriers remain asymptomatic for a long time, serving as a potential source for the transmission of the disease ${ }^{[13]}$. The aim of this investigation was to determine the prevalence of HTLV-1 and HTLV-2 among healthy individuals in Neyshabur, North-Eastern Iran, during 2010-2014.

\section{MATERIALS AND METHODS}

\section{Study population}

A total of 8054 healthy individuals from Neyshabur, North-Eastern Iran, were included in this study. Serum samples $(5 \mathrm{ml})$ were prepared from the individuals and stored at $-20^{\circ} \mathrm{C}$ until the ELISA test. 
Table 1. Age- and sex-based distribution of individuals and overall HTLV-positive cases

\begin{tabular}{cccccc}
\hline Variable & No. & $\begin{array}{c}\text { Positive cases } \\
(\%)\end{array}$ & $\begin{array}{c}\text { Odd Ratio } \\
(\mathbf{O R})\end{array}$ & $\begin{array}{c}\text { OR } \\
(\mathbf{9 5 \%} \mathbf{C})\end{array}$ & $\begin{array}{c}\boldsymbol{P} \\
\text { value }\end{array}$ \\
\hline Age (year) & & & & & \\
$0-19$ & 429 & $13(3.03)$ & Baseline & & $<0.0001$ \\
$20-29$ & 2556 & $49(1.92)$ & 0.625 & $0.336-1.163$ & \\
$30-39$ & 2018 & $88(4.36)$ & 1.459 & $0.807-2.637$ & \\
$\geq 40$ & 3051 & $377(12.36)$ & 4.512 & $2.571-7.918$ & \\
Gender & & & & & \\
Male & 1565 & $130(8.31)$ & & & \\
Female & 6489 & $398(6.13)$ & 1.386 & $1.128-1.704$ & 0.002 \\
\hline
\end{tabular}

\section{Serological assays and confirmation tests}

Serum samples were screened for the presence of specific antibodies against HTLV-1 and HTLV-2 by ELISA (Dia.Pro Diagnostic Bioprobes, Italy) according to the manufacturer's instructions ${ }^{[14]}$.

\section{Statistical analysis}

The SPSS software (version 20) was employed to analyze all data using chi-square and $t$-test. A $P<0.05$ was considered to be statistically significant.

\section{RESULTS AND DISCUSSION}

Of 8054 healthy individuals participated in the study, $1565(19.4 \%)$ and $6489(80.6 \%)$ were males and females, respectively. As shown in Table 1, the mean age of males and females was $46 \pm 3$ and $51 \pm 3$ years, respectively. The positivity of the samples was $6.55 \%$ (528 out of 8054), including $3.6 \%$ for HTLV-1 and $1.4 \%$ for HTLV-2. Table 2 indicates the total prevalence of HTLV-1 and HTLV- 2 in each year.

Previous studies have revealed that HTLV-1 is endemic in North-Eastern $\operatorname{Iran}^{[15]}$. Another study in Neyshabur has indicated that the prevalence of HTLV-
1 is $7.2 \%$ (35 out of 483$)^{[16]}$. However, the rate of HTLV-1 seropositivity has gradually decreased from $1.97 \%$ in 1996 to $0.26 \%$ in $2014^{[17-19]}$ in other regions of North-Eastern Iran. Similarly, the results of the present study demonstrated that the prevalence of HTLV-1 has decreased in Neyshabur from 2010 to 2014. In a survey carried out in Mashhad in 2012, the rate of HTLV-1 was detected to be $0.47 \%^{[20]}$. The seroprevalence of HTLV-1 did not exceed $0.19 \%$ in a study conducted by Safabakhsh et al. ${ }^{[7]}$. It seems that the reduction in HTLV-1 rate is mainly due to the improvement of blood donor selection and increased awareness among blood donors. However, in a study performed by Rafatpanah et al. ${ }^{[21]}$ in Mashhad, it was revealed that the prevalence of HTLV-1 is $20 \%$ (10 positive samples), although no evidence of HTLV-2 infection was found among immuneblotted samples and nested PCR.

In the current study, over $3 \%$ of healthy individuals were positive for HTLV-1 in all five years. To the best of our knowledge, there is a small number of published data regarding HTLV-2 prevalence in Iran. Also, a lower rate of positive HTLV-1 infection was identified in the present investigation, when compared to a previously study in Neyshabur ${ }^{[22]}$. This finding

Table 2. The annual prevalence of HTLV-1 and HTLV-2 investigated in this study

\begin{tabular}{llccc}
\hline Year & Number & HTLV-1 $(\%)$ & HTLV-2 $(\%)$ & Total percentage \\
\hline 2014 & $\begin{array}{l}\text { Positive: } 58 \\
\text { Total: } 1350\end{array}$ & 3.01 & ND & 3.01 \\
2013 & $\begin{array}{l}\text { Positive: } 94 \\
\text { Total: } 2337\end{array}$ & 4.11 & ND & 4.11 \\
2012 & $\begin{array}{l}\text { Positive: } 115 \\
\text { Total: } 2188\end{array}$ & 5.12 & ND & 5.12 \\
2011 & $\begin{array}{l}\text { Positive: } 117 \\
\text { Total: } 2057\end{array}$ & 5.13 & ND & 5.12 \\
2010 & $\begin{array}{l}\text { Positive: } 122 \\
\text { Total: } 1789\end{array}$ & 5.74 & ND & 5.74 \\
\hline
\end{tabular}

$\mathrm{ND}$, not determined 
highlights that Neyshabur is a major endemic region for HTLV-1. In addition, a higher prevalence of HTLV-1 was found in the age groups over 40 years, suggesting that there is a relationship between HTLVs and the age of individuals.

In the present study, a high rate of HTLV-1 among serum samples was detected using the ELISA test among healthy individuals in Neyshabur city during 2010-2014. The results from this study emphasize that HTLV is still an important endemic disease in Neyshabur. More importantly, the prevalence of HTLV-1 in Neyshabur was detected to be higher than other city (Mashhad) in all duration of this study, though being in a decreasing status compared to the previous reports.

\section{ACKNOWLEDGEMENTS}

The authors would like to thank the staffs of the Mashhad Academic Center for Education, Culture and Research (ACECR) laboratory in Neyshabour for their kind cooperation. This study was financially supported by Research and Technology Deputy of ACECR, Mashhad Branch (Iran).

CONFLICT OF INTEREST. None declared.

\section{REFERENCES}

1. Chenari M, Norouzi M, Ghalichi L, Rezaee A, Yari A, Alavian SM, Jazayeri SM. Characterization of overt and occult hepatitis B virus infection among HTLV-1 positive healthy carriers in the Northeast of Iran; An HTLV-I endemic area. Journal of medical virology 2014; 86(11): 1861-1867.

2. Pohanka M, Pavlis O, Pikula J. Galantamine effect on tularemia pathogenesis in a BALB/c mouse model. Iranian biomedical journal. 2012; 16(3): 156-161.

3. Doan CC, Le TL, Hoang NS, Doan NT, Le VD, Do MS. Differentiation of umbilical cord lining membranederived mesenchymal stem cells into endothelial-like cells. Iranian biomedical journal. 2014; 18(2): 67-75.

4. Cook LB, Taylor GP. HTLV-1 and HTLV-2 prevalence in the United States. Journal of infectious diseases 2014; 209(4): 486-487.

5. Farid R, Farid F, Rezaee SA. Prevalence of HTLV-1 infection in northeast of Iran. Retrovirology 2015; 12(Suppl 1): O7.

6. Mahzounieh M, Ghorani M, Karimi A, Pourgheysari B, Nikoozad R. Prevalence of human T-lymphotropic virus types I and II in patients with hematological disorders in Isfahan, Iran. Jundishapur journal of microbiology 2015; 8(6): 17201.

7. Safabakhsh H, Jalalian M, Karimi G. Seroepidemiology of Human T-Cell Lymphotropic Virus Type-1 (HTLV1) in Mashhad. Global journal of health science. 2014; 6(5): 99-104.

8. Senyuta N, Syrtsev A, Yamashita M, Stepina V, Susova O, Scherbak L, Pavlish O, Hayami M, Gurtsevitch V. Sero-epidemiologic and phylogenetic studies of HTLV-I infection in 2 countries of the Caspian Sea region. International journal of cancer 1998; 77(4): 488-493.

9. Carneiro-Proietti ABF, Sabino EC, Leão S, Loureiro P, Sarr M, Busch M, Proietti FA, Murphy EL. HTLV-1/2 prevalence in Brazilian blood donors: regional and demographic variation. Retrovirology 2011; 8(Suppl 1): A83.

10. Toro C, Rodés B, Aguilera A, Caballero E, Benito R, Tuset C, García J, De Lejarazu RO, Eirós JM, Calderón E, Rodriguez C, Soriano V; HTLV Spanish Study Group. Clinical impact of HTLV-1 infection in Spain: implications for public health and mandatory screening. Journal of acquired immune deficiency syndromes 2002; 30(3): 366-368.

11. Kwon SY, Lim AH, Park JY, Han SH, Cho NS. Seroprevalence of human T-lymphotropic virus type 1 and 2 in Korean blood donors. Journal of medical virology 2008; 80(10): 1864-1867.

12. Satake M, Yamaguchi K, Tadokoro K. Current prevalence of HTLV-1 in Japan as determined by screening of blood donors. Journal of medical virology 2012; 84(2): 327-335.

13. Tanajura D, Castro N, Oliveira P, Neto A, Muniz A, Carvalho NB, Orge G, Santos S, Glesby MJ , Carvalho EM. Neurological manifestations in human T-cell lymphotropic virus type 1 (HTLV-1)-infected individuals without HTLV-1-associated myelopathy/ tropical spastic paraparesis: A longitudinal cohort study. Clinical infectious diseases 2015; 61(1): 49-56.

14. Mortezaie Z, Bouzari M, Roghanian R. Evaluating the frequency of HTLV-I/II infection among blood donors, major thalassemic patients and individuals infected with hepatitis $\mathrm{B}$ and $\mathrm{C}$ viruses in Isfahan, Iran. Iranian journal of blood and cancer 2012; 4(2): 75-80.

15. Rezvan H, Abolghassemi $H$, Kafiabad SA. Transfusion-transmitted infections among multitransfused patients in Iran: a review. Transfusion Medicine 2007; 17(6): 425-433.

16. Hedayati-Moghaddam M, Fathimoghadam F, Mashhadi IE, Soghandi L, Bidkhori H. Epidemiology of HTLV-1 in Neyshabour, Northeast of Iran. Iranian Red Crescent medical journal 2011; 13(6):424-427.

17. Safabakhsh HR, Karimi G, Hatami H. The prevalence of HTLV-1 infection in blood donation volunteers in Mashhad. Journal of School of Public Health and Institute of Public Health Research. 2014; 11(4): 85-94.

18. Tarhini M, Kchour G, Zanjani DS, Rafatpanah H, Otrock ZK, Bazarbachi A, Farid R. Declining tendency of human T-cell leukaemia virus type I carrier rates among blood donors in Mashhad, Iran. Pathology 2009; 41(5): 498-499.

19. Sani AT. Serologic prevalence of HTLV among blood donors in Mashhad (northeastern Iran). Archives of Iranian medicine 2001; 4(1): 25.

20. Hatami H, Karimi G, Safabakhsh H. Seroepidemiologic 
prevalence of HTLV in voluntary blood donors in Mashhad. Scientific journal of Iranian blood transfusion organization. 2012; 9(2): 149-159.

21. Rafatpanah H, Fathimoghadam F, Shahabi M, Eftekharzadeh I, Hedayati-Moghaddam M, Valizadeh N, Tadayon M, Shamsian SA, Bidkhori H, Miri R, Bazarbachi A. No Evidence of HTLV-II Infection Among Immonoblot Indeterminate Samples Using
Nested PCR in Mashhad, Northeast of Iran. Iranian journal of basic medical sciences 2013; 16(3): 229-234.

22. Bidkhori H, Hedayati-Moghaddam M, FathiMoghaddam F, Soghandi L, Bakhtiari H, Rezaie A. High Prevalence of HTLV-1 Infection among Hemodialysis Patients in Neyshabour, Northeast of Iran. Iran journal of allergy and asthma immunology 2013; 12(Suppl 9): 38 . 